\title{
Synthesis and characterization of multiwalled CNT-PAN based composite carbon nanofibers via electrospinning
}

\author{
Narinder Kaur ${ }^{1 *}$, Vipin Kumar ${ }^{1}$ and Sanjay R. Dhakate ${ }^{2}$
}

\begin{abstract}
Electrospun fibrous membranes find place in diverse applications like sensors, filters, fuel cell membranes, scaffolds for tissue engineering, organic electronics etc. The objectives of present work are to electrospun polyacrylonitrile (PAN) nanofibers and PAN-CNT nanocomposite nanofibers and convert into carbon nanofiber and carbon-CNT composite nanofiber. The work was divided into two parts, development of nanofibers and composite nanofiber. The PAN nanofibers were produced from $9 \mathrm{wt} \%$ PAN solution by electrospinning technique. In another case PAN-CNT composite nanofibers were developed from different concentrations of MWCNTs (1-3wt\%) in 9 wt\% PAN solution by electrospinning. Both types of nanofibers were undergone through oxidation, stabilization, carbonization and graphitization. At each stage of processing of carbon and carbon-CNT composite nanofibers were characterized by SEM, AFM, TGA and XRD. It was observed that diameter of nanofiber varies with processing parameters such as applied voltage tip to collector distance, flow rate of solution and polymer concentrations etc. while in case of PAN-CNT composite nanofiber diameter decreases with increasing concentration of CNT in PAN solution. Also with stabilization, carbonization and graphitization diameter of nanofiber decreases. SEM images shows that the minimum fiber diameter in case of 3 wt\% of CNT solution because as viscosity increases it reduces the phase separation of PAN and solvent and as a consequence increases in the fiber diameter. AFM images shows that surface of film is irregular which give idea about mat type orientation of fibers. XRD results show that degree of graphitization increases on increasing CNT concentration because of additional stresses exerting on the nanofiber surface in the immediate vicinity of CNTs. TGA results shows wt loss decreases as CNT concentration increases in fibers.
\end{abstract}

Keywords: Polyacrylonitrile, Nanocyl multiwalled carbon nanotubes

\section{Background}

Electrospinning is a most efficient technique to generate fibers with submicron diameters. Electrospun nanofibers mats are more promising because of high surface area and porosity, which have applications in air filtration, tissue engineering, drug delivery, and energy storage materials (Doshi and Reneker 1995; Formhals 1944). Reliable production of porous nanofibers in a simple and inexpensive way has been attempted by number of groups (Xia and Li 2006) showed that, by using a coaxial

\footnotetext{
${ }^{*}$ Correspondence: narinder.rani@gmail.com

1 Department of Physics, Krishna Institute of Engineering and Technology, Ghaziabad, India

Full list of author information is available at the end of the article
}

spinneret with miscible solvents and immiscible polymers, highly porous fibers could be obtained (Xia and Li 2006). Since the beginning of this century, researchers all over the world have been re-looking at a century old process (Cooley and Morton 1902) currently it is known as electrospinning (Hagewood 2004). Probably unknown to most researchers for most of the last century, electrospinning is able to produce continuous fibers from the submicron diameter down to the nanometer diameter. It was not until the mid-1990s with interest in the field of nanoscience and nanotechnology that researchers started to realize the huge potential of the process in nanofiber production (Doshi and Reneker 1995). Nanofibers and nanowires with their huge surface area to volume ratio, 
about a thousand times higher than that of a human hair, have aspect area.

Carbon fibers are manufactured through heating and stretching treatments (Shenoy et al. 2005). Polyacrylonitrile (PAN) and pitch are the two most common raw products used to produce carbon fibers. PAN is a synthetic fiber that is pre manufactured and wound onto spools, and pitch is a coal-tar petroleum product that is melted, spun, and stretched into fibers. The production of carbon nano fibrils will achieve a unique property (Mechanical, Electrical and Physical) by keeping the same amount of crystallite size from core to skin and increasing the surface area per unit volume which mimic the same structure of MWCNT (Saito et al. 1998).

This paper reports our findings on testing this concept by electrospinning mixtures of Chopped PAN co-polymer micro fibers of diameter $12.5 \mu \mathrm{m}$ having polyacrylonitrile with a $6 \%$ monomer methyl methacrylate and $N, N$-dimethylformamide (DMF) of $99 \%$ purity (B. Pt. $=157^{\circ} \mathrm{C}$ ) and also Functionalized Carbon Nanotubes (CNT) are used as fillers (Haddon and Itkis 2008). Fibers uniformity and diameter (75-1500 $\mathrm{nm}$ ) have been shown to increase with increasing concentrations of CNT by controlling solution and processing parameters in whole study (Haddon and Itkis 2008).

\section{Experimental details} Materials

Polymer Chopped PAN co-polymer micro fibers of diameter $12.5 \mu \mathrm{m}$ having polyacrylonitrile with a $6 \%$ monomer methyl methacrylate was used as source of PAN. Molecular weight of PAN is $53.0626 \pm 0.0028 \mathrm{~g} /$ mol, C $67.91 \%$, H 5.7 \%, N $26.4 \%$.

Solvent $\quad N, N$-dimethylformamide (DMF) of $99 \%$ purity (B. Pt. $=157^{\circ} \mathrm{C}$ ) from Fisher Scientific.

Filler Functionalized Carbon Nanotubes (CNT) from Nanocyl.

\section{Preparation of PAN nanofibers}

The $9 \mathrm{wt} \%$ PAN copolymer solution was prepared by taking $0.9 \mathrm{~g}$ chopped PAN microfibers was socked in $9.1 \mathrm{~g}$ of DMF and mix with glass rod. The mix was sonicated in ultrasonicator till it gives a clear solution and stirred continuously on magnetic stirrer for $5 \mathrm{~h}$ to mix well the contents.

\section{Preparation of PAN-CNT composite nanofibers}

PAN-CNT (1-3 wt\%) $9 \%$ solutions were prepared in following steps: at first $0.01 \mathrm{~g}$ functionalized CNTs were dispersed in $\mathrm{N}, \mathrm{N}$-dimethylformamide. The mixture was kept in sonicator for 5-8 h to break bundles of CNTs and magnetic stirring to disperse well CNTs in DMF. A good dispersion was achieved in $7 \mathrm{~h}$. Calculated quantity of PAN copolymer chopped microfibers were added in dispersion solution and kept on magnetic stirrer for overnight to mix well the polymer in CNT dispersion. Solution was sonicated for $1 \mathrm{~h}$ and then electrospun with ESPIN instrument at voltage $15 \mathrm{kV}$, flow rate $0.2 \mathrm{ml} / \mathrm{h}$, drum speed $2000 \mathrm{rpm}$, distance $15 \mathrm{~cm}$ to produce PAN$\mathrm{CNT}$ composite nanofibers. It was difficult to prepare solution using higher concentration of CNT. The problem faced was that, in high quantity of CNTs polymer not get dispersed well and form a solid mass. So both CNTs and polymer were dispersed in DMF separately. CNTs and DMF mixture was sonicated for $1 \mathrm{~h}$ till all bundles breakup and then kept on magnetic stirrer, good dispersion observed in sun light. Polymer was soaked in DMF well and sonicated for $1 \mathrm{~h}$. Then it was kept on magnetic stirrer till a clear solution was obtained. Same procedure was carried out for PAN-CNT concentrations (2-3 wt\%).

Both types of nanofibers were undergone through oxidation, stabilization, carbonization and graphitization. At each stage of processing of carbon and carbon-CNT composite nanofibers were characterized by SEM, AFM, $\mathrm{XRD}$ and TGA.

\section{Results and discussions \\ SEM analysis}

The concentration, viscosity, and conductivity of the solution as well as the applied voltage and distance between the charged electrode and the grounded target were adjusted in order to obtain stable electrospinning jet (Drozin 1955). Figure 1 shows the micrograph of electrospun nanofibers (Gupta and Wilkes 2003) prepared from

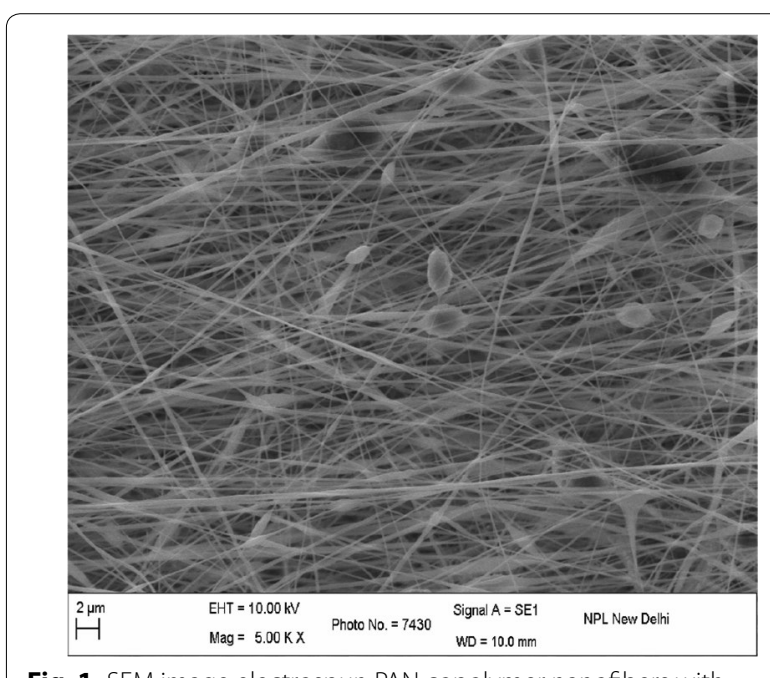

Fig. 1 SEM image electrospun PAN copolymer nanofibers with $9 \mathrm{wt} \% 1000 \mathrm{rpm}$, flow rate $0.2 \mathrm{ml} / \mathrm{h}$, applied voltage $15 \mathrm{kV}, 10 \mathrm{~cm}$ 
solution of $9 \mathrm{wt} \%$ of PAN concentration with flow rate $0.2 \mathrm{ml} / \mathrm{h}$ and collector speed $1000 \mathrm{rpm}$, applied voltage $15 \mathrm{kV}$ in which tip to collector distance varies from 10 to $20 \mathrm{~cm}$ at $\mathrm{EHT}=10 \mathrm{kV}$ and at different magnification. It is observed that with increasing the tip to collector distance, fiber diameter decreases. At tip to collector distance $10 \mathrm{~cm}$, fiber diameter is in the range of $100-175 \mathrm{~nm}$ and decreases to $75-175 \mathrm{~nm}$ on increasing distance to $15 \mathrm{~cm}$. In this case the variation is comparatively less as compared to tip to collector distance $10 \mathrm{~cm}$. This variation in diameter is due to the instability in jet due to change in repulsive forces (Baumgarten 1971). Figure 2 shows the SEM image of PAN-CNT composite with $1 \%$ MWCNTs. The CNTs are aligned in nanocomposite, which is distinguished by color of PAN nanofibers. The presence of black color in fiber, it indicates the presence of CNTs in nanofibers. Since the MWNTs possess a high electron density compared with the PAN polymer matrix, the nanotubes appear as darker tubular structures embedded in the PAN distorted nanofibers with black impression. The stabilization is one of the important steps and play important role in controlling the properties of final fibers (Ramakrishna et al. 2005; Ko et al. 2003; Khil et al. 2005). Figure 3 shows the stabilized PAN-CNT $3 \mathrm{wt} \%$ nanofibers. The oxidative stabilization was carried out at $310{ }^{\circ} \mathrm{C}$ and kept isothermally for $1 \mathrm{~h}$. It is found that, on stabilization fibers diameter decreases as compared as spun nanofiber diameter. Figure 4 shows the SEM image of carbonized fiber with $3 \mathrm{wt} \%$ of CNTs incorporated during the processing. From the figure it is observed that there visible difference in the morphology of carbon-CNT composite nanofibers. At higher content of CNTs, CNTs are might be not individually aligned during electrospinning. Therefore, from the surface of carbon-CNTs nanofiber, it is visible bundles (He et al. 2004) in the range of $50-100 \mathrm{~nm}$ in the fiber of diameter 300-400 nm (Guo et al. 1955).

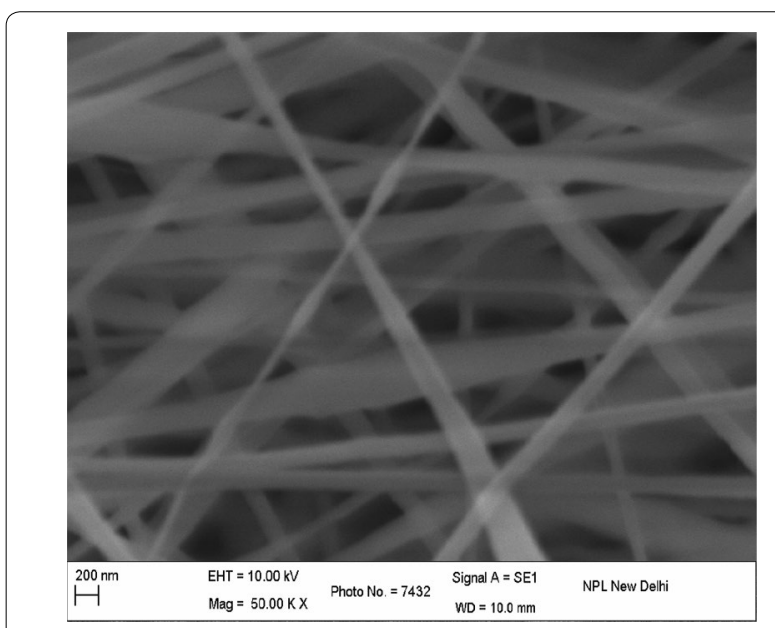

Fig. 2 SEM image PAN-CNT nanocomposite with $1 \%$ MWCNTS

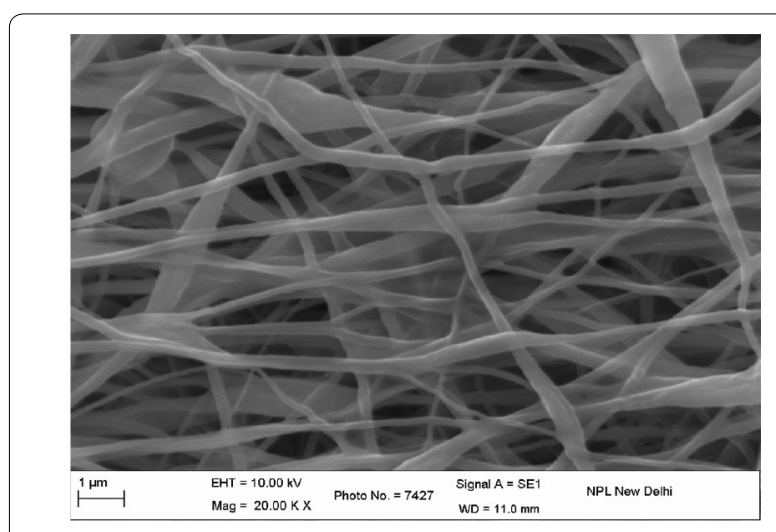

Fig. 3 SEM images of electrospun PAN-CNT stabilized nanofibers at $310^{\circ} \mathrm{C}$ with $3 \mathrm{wt} \%$ of CNT and drum speed $2000 \mathrm{rpm}$, distance $10 \mathrm{~cm}$, flow rate $0.3 \mathrm{ml} / \mathrm{h}$, voltage $15 \mathrm{kV}$

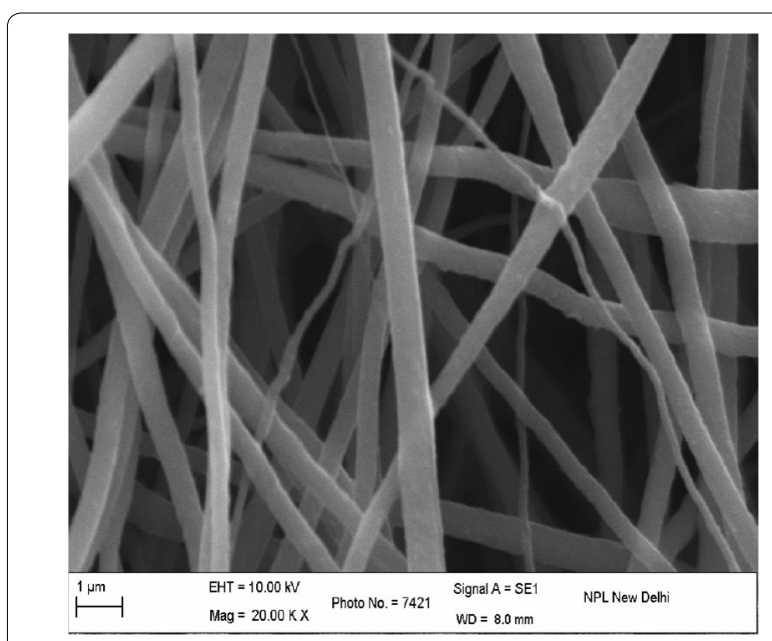

Fig. 4 SEM images of electrospun PAN-CNT carbonized nanofibers at $1000^{\circ} \mathrm{C}$ with $3 \mathrm{wt} \%$ of CNT and drum speed $2000 \mathrm{rpm}$, distance $10 \mathrm{~cm}$, flow rate $0.3 \mathrm{ml} / \mathrm{h}$, voltage $15 \mathrm{kV}$

\section{AFM analysis}

Figure 5 shows 2D \& 3D AFM images of PAN copolymer nanofibers mat of over an area $5 \mu \mathrm{m} \times 5 \mu \mathrm{m}$ of concentration $9 \mathrm{wt} \%$ in DMF for nanofiber, stabilized nanofiber and carbonized nanofiber. This shows that nanofibers are randomly oriented and surface roughness of film is $32.3 \mathrm{~nm}$. The surface area of film is $23 \mu \mathrm{m}^{2}$ and from bar analysis of surface of film, nanofibers have diameter in the range $75-100 \mathrm{~nm}$ \& depth of film is $273 \mathrm{~nm}$ (Ramakrishna et al. 2005; Samatham et al. 2006). But on carbonization, surface area decreases to $22.4 \mu \mathrm{m}^{2}$ and surface roughness to $27.0 \mathrm{~nm}$. The depth of film also decreases to $268 \mathrm{~nm}$ and fiber diameter to $70-90 \mathrm{~nm}$. The change in depth and diameter is related to shrinkage of fiber film due to cyclization reactions take place at higher temperature. Figure 6 shows the AFM images of 

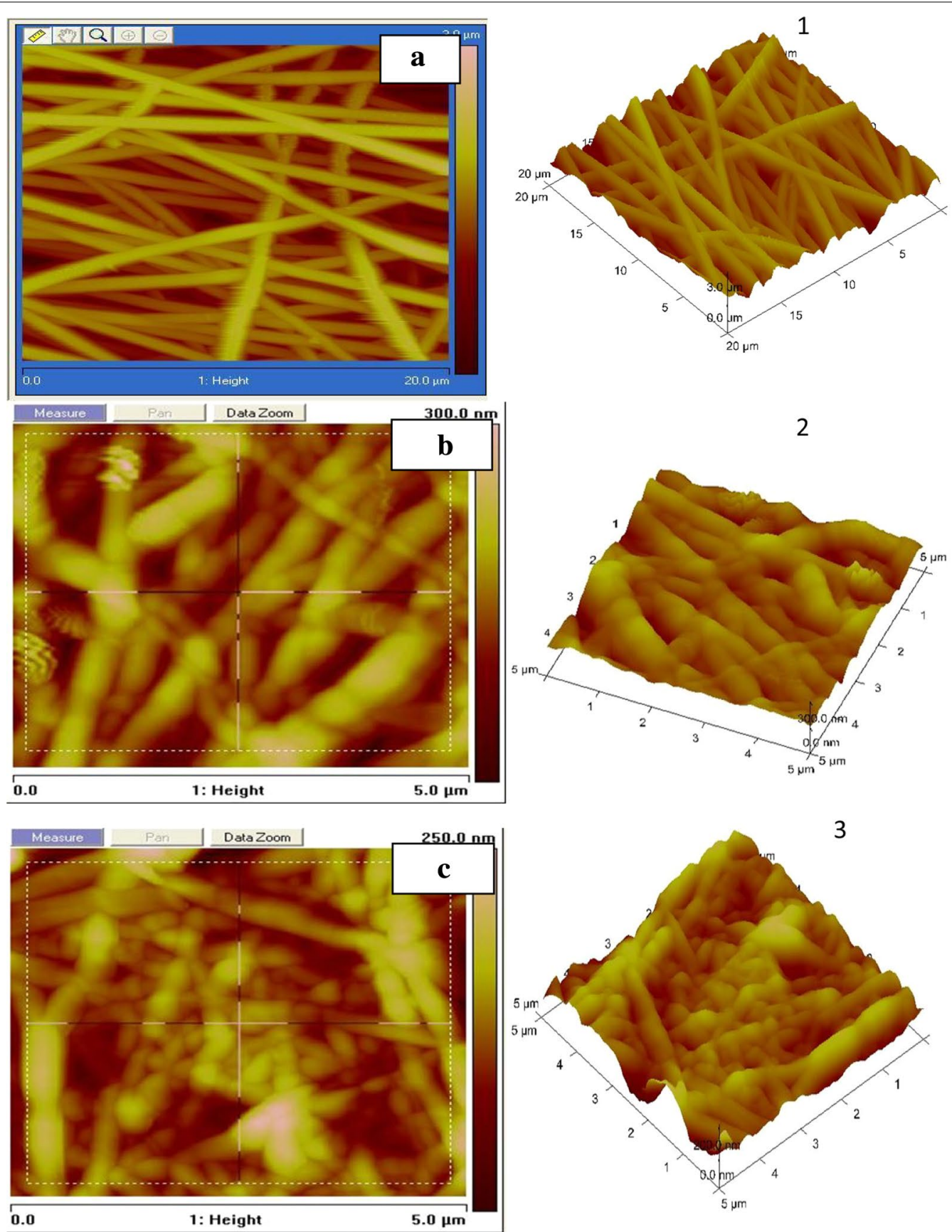

Fig. 5 2D \& 3D AFM images of PAN copolymer nanofibers mat of concentration 9 wt $\%$ in DMF. a(1) nanofibers, $\mathbf{b}(\mathbf{2})$ stabilized, $\mathbf{c}(\mathbf{3})$ carbonized

PAN-CNT 3 wt\% carbonized fibers shows two kinds of regions, lighter and darker. The lighter regions are related to the highest points, and the darker regions are related to pores and valleys. This suggests that surface of film become more asymmetric on carbonization sharp spike in the picture is due to non orientation of fibre surface in one plane. It shows that surface of film is irregular which give idea about mat type orientation of fibers and high percentage of CNT was easily seen from fibre sheet which has darker black color. Diameter of fibre decreases due to presence of embedded CNT's because diameter of Taylor cone is reduced due to high electron density. In carbonization there occur the change in depth and diameter due to shrinkage of fiber film due to cyclization 

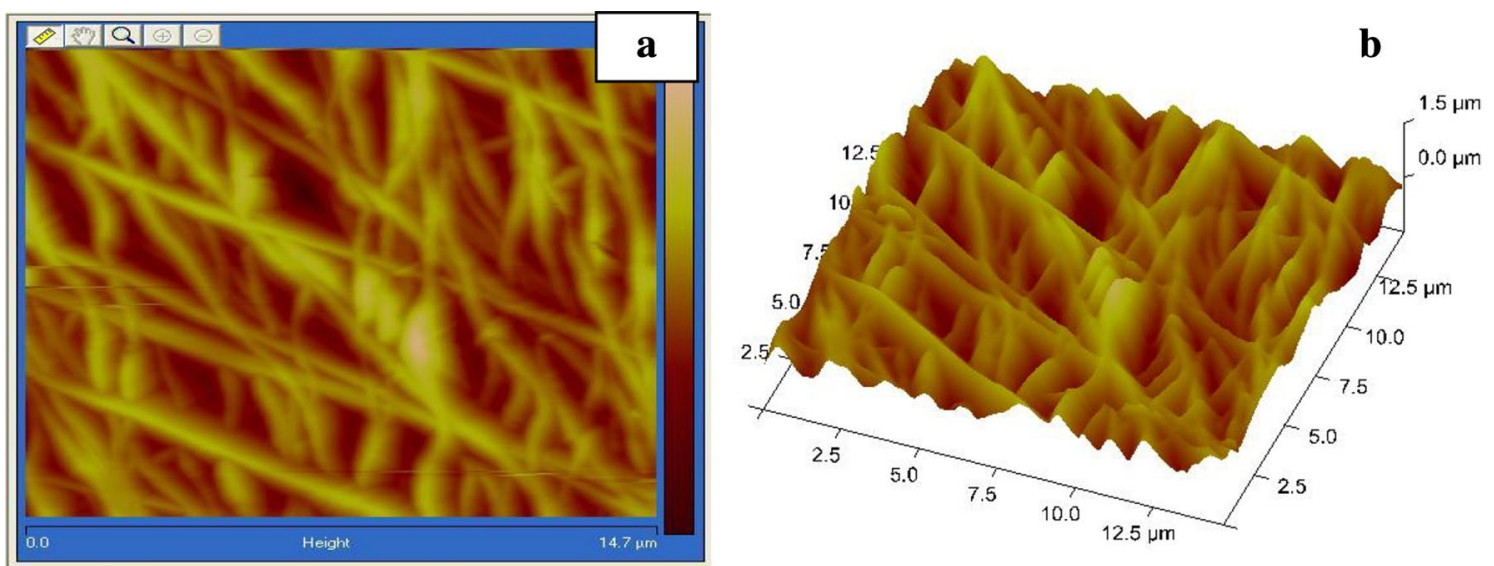

Fig. 6 AFM images of PAN-CNT carbonized from concentration 3 wt\% of CNT, tip to collector distance $10 \mathrm{~cm}$, drum speed $2000 \mathrm{rpm}$, a $2 \mathrm{D}$ image, b $3 \mathrm{D}$ image

reactions take place at higher temperature (Ko et al. 2003; Hendricks et al. 1964; Taylor 1969).

\section{XRD analysis}

Figures 7 and 8 shows XRD patterns of PAN nanofibers and carbon nanofibers. PAN fiber shows strong diffraction peak centered around $2 \theta$ angle of $16.67^{\circ}$ and $29.462^{\circ}$, these two peaks represents the X-ray reflection of the (110) of a hexagonal structure and (112) crystallographic planes in PAN. However, in case of the PAN-CNT 1 wt\% nanofibers, curve " $\mathrm{B}$ ", the peak centered on $2 \theta$ angle of $16.67^{\circ}$ and $29.462^{\circ}$, these two peaks represents the X-ray reflection of the (110) of a hexagonal structure and (112), and $2 \theta$ angle of $44.37^{\circ}$ represents the X-ray reflection of the (004) this is due to presence of CNT. In case of the PAN-CNT 2-3 wt\% nanofibers, curve " $C$ ", the peak centered on $2 \theta$ angle of $16.67^{\circ}$ and $29.462^{\circ}$, these two peaks represents the X-ray reflection of the (110) of a hexagonal structure and (112), and $2 \theta$ angle of $44.37^{\circ}$ represents the X-ray reflection of the (004) this is due to presence of CNT. But intensity of peaks is very high as comparison to $1 \mathrm{wt} \%$ of CNT (Hagewood 2004). In carbonized nanofibers intense diffraction peak as compared to stabilize fibres around $2 \theta$ angle of $24^{\circ}-26^{\circ}$ is attributed to (002) crystallographic plane of graphite crystallite. Degree of graphitization is determined from XRD results (Kim and Reneker 1999) by using formula $\left(\mathrm{g}=\left(\left(0.3440-\mathrm{d}_{200}\right) /(0.3440-0.3354)\right) \times 100\right.$ and $\mathrm{d}_{200}=\mathrm{n} \lambda / 2 \sin \theta$ where $\lambda$ is wavelength, $\theta$ is diffraction angle and 0.3440 is interlayer spacing of fully non graphitized carbon $(\mathrm{nm})$. Degree of graphitization for PAN nanofibers is $-20 \%$ and for PAN-CNT nanofibers is -41.86 . Degree of graphitization increases due to presence of CNT in fibers.

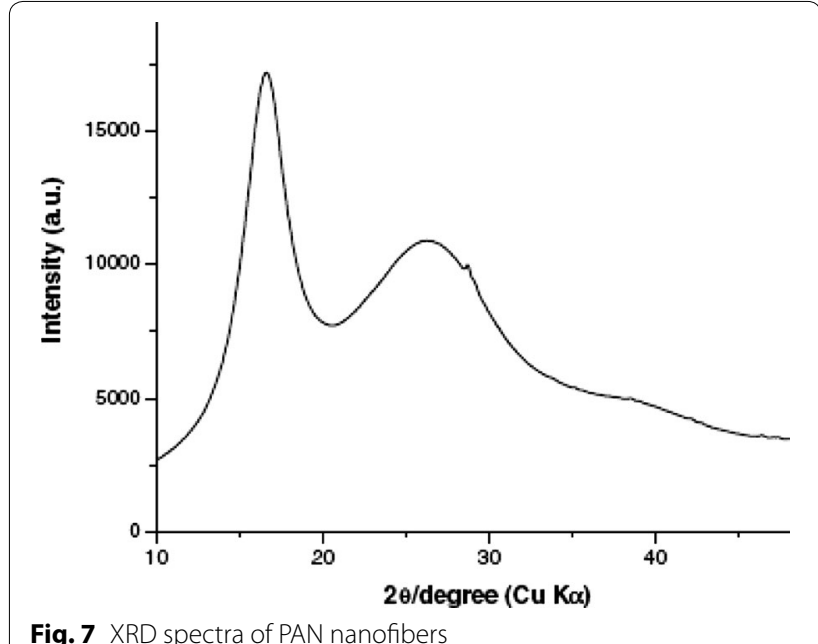

Fig. 7 XRD spectra of PAN nanofibers

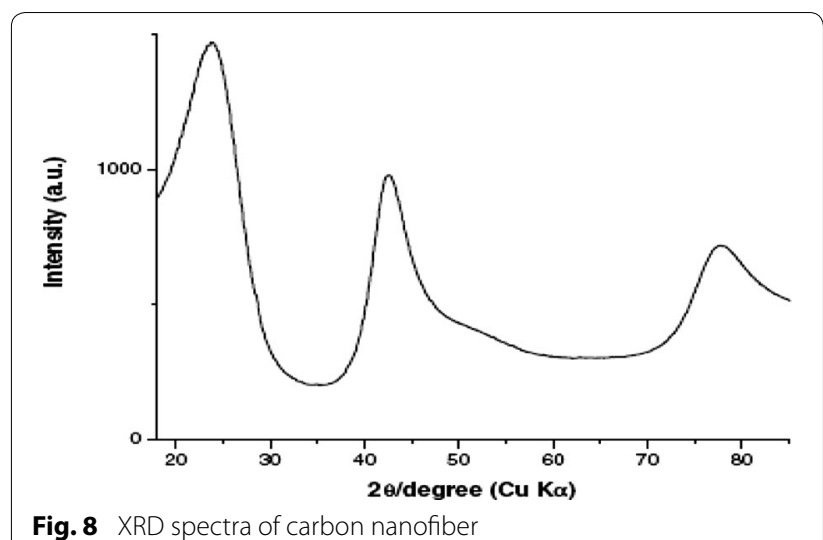




\section{TGA analysis}

Mettle Toledo TGA star system was used for TGA analysis up to $1000{ }^{\circ} \mathrm{C}$ temp and rate of $10^{\circ} / \mathrm{c}$ in the nitrogen atmosphere at flow rat $10 \mathrm{ml} / \mathrm{min}$. Figure 9 shows that in case of $9 \mathrm{wt} \%$ concentration PAN copolymer nanofibers after heating at $1000{ }^{\circ} \mathrm{C}$ residue remaining found to be $68.158 \%$ i.e. wt loss was $31.842 \%$. The wt loss in nanofibers is very less which shows stability increase in nano size of fibers. This may be due to the high surface area of nanofibers which provide stability as well as complete stabilization reaction. Figure 10 shows that PAN-CNT stabilized nanofibers after heating at $310{ }^{\circ} \mathrm{C}$ residue remaining found to be $21.8283 \%$ i.e. wt loss was $78.1717 \%$. This wt loss is more as in case of PAN$\mathrm{CNT}$ stabilized. This may be again due to the decrease in fiber size because as concentration of CNT increases, fiber diameter also decrease and surface area increase. This may be due to the high surface area of nanofibers which provide stability as well as complete stabilization reaction.

Figure 11 shows that PAN-CNT carbonized nanofibers after heating at $310{ }^{\circ} \mathrm{C}$ residue remaining found to be 60.8283 \% i.e. wt loss was 39.1717 \% (Yarin et al. 2001).

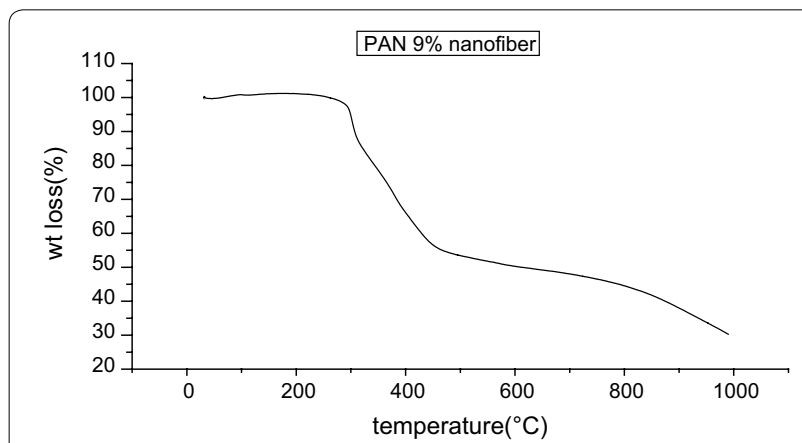

Fig. 9 TGA graph of PAN nanofibers from concentration $9 \mathrm{wt} \%$, drum speed $2000 \mathrm{rpm}$, tip to collector distance $10 \mathrm{~cm}$

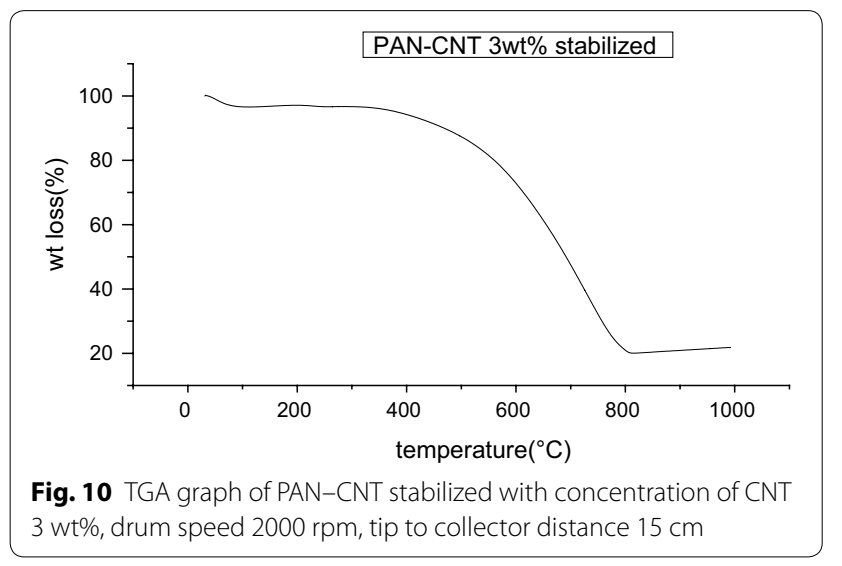

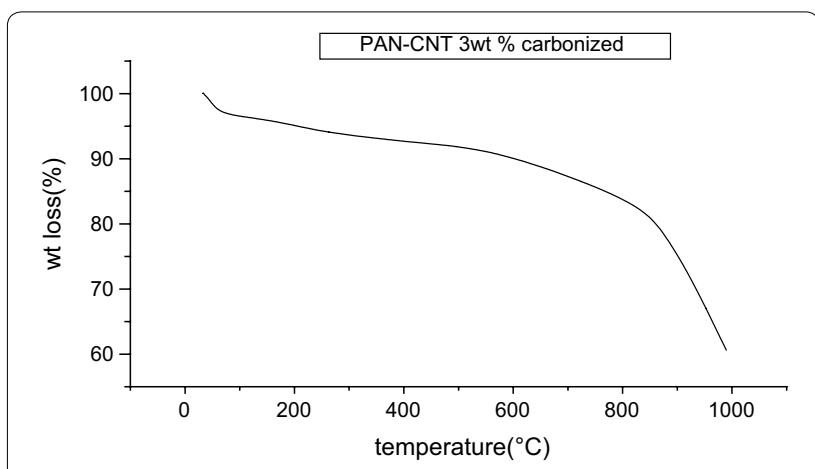

Fig. 11 TGA graph of PAN-CNT carbonized with concentration of CNT 3 wt\%, drum speed $2000 \mathrm{rpm}$, tip to collector distance $15 \mathrm{~cm}$

This wt loss is less in case of PAN-CNT carbonized as comparison to PAN-CNT stabilized because of increase in stability in structure (Teraoka 2002; Huang et al. 2003), and removal of nitrogen, water and hydrogen. $\mathrm{HCN}$ and another gases and also carbon content increases on carbonization (Zhou and Liu 2010).

\section{Conclusions}

In the present study we have successfully used the electrospinning for the synthesis of PAN-CNT carbon nanofibers. SEM images shows that the fiber diameter varies from 75 to $1500 \mathrm{~nm}$ on increasing concentration of CNT. The presence of black color in fiber, it indicates the presence of CNTs in nanofibers. AFM images show that the surface morphology of the composite nanofibers is smooth at lower concentration of MWCNT but rough at high concentration of MWNTs. Since the MWNTs possess a high electron density compared with the PAN polymer matrix, the nanotubes appear as darker tubular structures embedded in the PAN nanofibers. It is also seen that on Stabilization fibers diameter decreases due to shrinkage in fibers. Degree of graphitization for PAN nanofibers is $-20 \%$ and for PAN-CNT nanofibers is -41.86 . Degree of graphitization increases due to presence of CNT in fibers. TGA results shows that wt loss is small in case of PAN nanofibers because of high surface area of nanofibers while in case of carbonized PANMWCNT carbon nanofibers wt loss is small as comparison to PAN-CNT stabilized because of increase in stability in structure, and removal of nitrogen, water and hydrogen. HCN and another gases and also carbon content increases on carbonization.

Authors' contributions

All authors have equal contribution in carrying out research work as well as in writing work of manuscript. All authors read and approved the final manuscript.

\section{Author details}

${ }^{1}$ Department of Physics, Krishna Institute of Engineering and Technology, Ghaziabad, India. ${ }^{2}$ National Physical Laboratory, New Delhi, India. 


\section{Competing interests}

The authors declare that they have no competing interests.

Received: 22 December 2015 Accepted: 24 March 2016

Published online: 19 April 2016

\section{References}

Baumgarten PK (1971) Electrostatic spinning of acrylic microfibers. J Colloid Interface Sci 36:71-79

Ko F, Gogots Y, Ali A, Naguib N, Ye H, Yang GL, Li C, Wills P (2003) Electrospinning of continuous carbon nanotubes-filled nanofibers yarns. Adv. Matter 15(4):1161-1165

Cooley, Morton WJ (1902) Method of dispensing fluids, US Patent 705,691

Doshi J, Reneker DH (1995) Electrospinning process and application of electrospun fibers. J Electrost 35:151-160

Drozin VG (1955) J Colloid Sci 10:158-164

Formhals A (1944) US patent, 2,349,950

Guo T, Nikolaev P, Thess A, Colbert DT, Smalley RE (1995) Catalytic growth of single-walled manotubes by laser vaporization. Chem Phys Lett 243(1):49-54

Gupta P, Wilkes GL (2003) Some investigations on the fiber formation by utilizing a side-by-side bicomponent electrospinning approach. Polymer 44:6353-6359

Haddon R, Itkis M (2008) Measurement issues in single wall carbon nanotubes. NIST, pp 20

He JH, Wan YQ, Yuc JY (2004) Application of vibration technology to polymer electrospinning. Int J Nonlinear Sci Numer Simul 5:243-248

Hagewood J (2004) Production of polymeric nanofibers. Inter Fiber J 19(1):48-50

Hendricks CD, Carson RS, Hogan JJ, Schneider JM (1964) Photomicrography of electrically sprayed heavy particles. AIAA J 2:733-737
Huang Z-M, Zhang Y-Z, Kotaki M, Ramakrishna S (2003) A review on polymer nanofibers by electrospinning and their applications in nanocomposites. Compos Sci Technol 63:2223-2253

Khil MS, Bhattarai SR, Kim HY, Kim SZ, Lee KH (2005) Novel fabricated matrix via electrospinning for tissue engineering. J Biomed Mater Res B 72:117-124

Kim J-S, Reneker DH (1999) Mechanical properties of composites using ultrafine electrospun fibers. Polym Compos 20:124-131

Ramakrishna S, Fujihara K, Teo WE, Lim TC, Ma Z (2005) An introduction to electrospinning and nanofibers. World Scientific Publishing C. Pte. Ltd., $7-15,279-338$

Saito R, Dresselhaus G, Dresselhaus MS (1998) Physical properties of carbon nanotubes, vol 35. Imperial College Press, London, pp 73-81

Samatham R, Kim KJ, Nam J-D, Whisman N, Adams J (2006) Electrospun nanoscale polyacrylonitrile artificial muscle. Smart Mater Struct 15:N152-N156

Shenoy SL, Bates WD, Frisch HL, Wnek GE (2005) Role of chain entanglements on fiber formation during electrospinning of polymer solutions: good solvent, non-specific polymer-polymer interaction limit. Polymer 46:3372-3384

Taylor Gl (1969) Electrically driven jets. Proc R Soc Lond Ser A 313:453-475

Teraoka I (2002) Polymer solutions, an introduction to physical properties. Wiley, New York

Xia Y, Li D (2006) US20060226580

Yarin AL, Koombhongse S, Reneker DH (2001) Taylor cone and jetting from liquid droplets in electrospinning of nanofibers. J Appl Phys 90:4836-4846

Zhou Z, Liu K (2010) Graphitic carbon nanofibers developed from bundles of aligned electrospun PAN nanofibers containing phosphoric acid. Polymer 51:2360-2367

\section{Submit your manuscript to a SpringerOpen ${ }^{\circ}$ journal and benefit from:}

- Convenient online submission

- Rigorous peer review

- Immediate publication on acceptance

- Open access: articles freely available online

- High visibility within the field

- Retaining the copyright to your article

Submit your next manuscript at $\boldsymbol{\nabla}$ springeropen.com 